\title{
Does Technology Impact on Teaching Styles or Do Teaching Styles Impact on Technology in the Delivery of Higher Education?
}

\author{
Tony Jewels \\ Queensland University \\ of Technology, \\ Brisbane, Australia
}

\section{t.jewels@qut.edu.au}

\author{
Carmen de Pablos \\ Heredero \\ Rey Juan Carlos \\ Universidad, Madrid, \\ Spain
}

cpablos@fcjs.uric.es

\author{
Marilyn Campbell \\ Queensland University of \\ Technology, \\ Brisbane, Australia
}

\begin{abstract}
Although there are many teaching styles in higher education, they can usually be reduced to two: the traditional, on campus attendance, lecturing, student-passive style and the newer, distance education, self-paced, student-active style. It is the contention of this paper, illustrated by two case studies of one Spanish and one Australian university, that the differences in technology seem to have evolved due to these different teaching styles. On the other hand, both institutions seem to be in the same stage of technological implementation, although the technological product appears different. A discussion is provided to consider the interaction effects in practice, teaching styles and institutional adoption stage on web based technologies in these two universities.
\end{abstract}

Keywords: Teaching styles, web based technologies, university lecturing

\section{Introduction}

New technological environments can promote a great number of efficiencies and potential benefits in the way universities show and process the information required in their teaching functions. Block and Dobell, (1999), forecasted that $80 \%$ of higher education providers would offer some kind of virtual education by 2002, although admitting that their extension and reach would vary. Areas of research relating to web-based technologies for teaching purposes include virtual teams (Knoll \& Jarvenpaa, 1995), group work with technological tools (Alavi, 1994; Alavi, Wheeler, \& Valacich, 1995), interactions in class with the use of computers (Leidner \& Fuller, 1997) and the sending and receiving of institutional material (Leidner \& Jarvenpaa, 1993).

In the last ten years there has been a dramatic increase in the development of the use of webbased networks for teaching purposes. The introduction of web-based networks within institutions of higher education can have profound implications on how knowledge is shared between stakeholders. However, with the establishment of these new environments, new cognitive skills are

Material published as part of this journal, either on-line or in print, is copyrighted by Informing Science. Permission to make digital or paper copy of part or all of these works for personal or classroom use is granted without fee provided that the copies are not made or distributed for profit or commercial advantage AND that copies 1) bear this notice in full and 2) give the full citation on the first page. It is permissible to abstract these works so long as credit is given. To copy in all other cases or to republish or to post on a server or to redistribute to lists requires specific permission from the publisher at Publisher@InformingScience.org needed. A new paradigm for the introduction of multimedia tools in general education and particularly in distance education, demands from both students and lecturers the development of new competencies that consider communication from a different perspective. Thus teaching styles might be 
influenced by these technologies or the technologies might influence teaching styles.

Furthermore, organisations have adopted information technology in three distinct stages: to improve productivity and quality (automate stage), create and maintain an advantage (informate stage) and finally redesign business processes to better support company strategy (transformate stage), (Frenzel, 1999) which Venkatraman, (1994) summarises as evolutionary and revolutionary levels. The stage at which universities are operating might also affect their teaching styles using web-based technologies or the teaching styles might determine the technology.

\section{Descriptions of the Universities}

A case study comparison of how two unrelated universities are meeting the opportunities and challenges that these possibilities offer must first describe the characteristics of each university to determine if technology is the driving force or teaching styles or if pedagogical considerations are influencing the technology.

\section{The National Distance Learning University (UNED) of Spain}

The National Distance Learning University (UNED) was created legislatively by Act 2310/72 on August $18^{\text {th }}, 1972$ in Spain. The principal reason for the Act was to provide access to higher education for people who because of time, work or distance were unable to attend a traditional campus based university. This university is entirely based on distance teaching and learning, requiring the same general conditions of instructional systems but needing a specific methodology not restricted by space or time. It functions nationally, providing innovative teaching and learning for the delivery of higher education. Today, UNED offers sixteen different university faculty courses, which include special courses for people over 25 years of age, six masters degrees, 16 different titles as upper university specialist, 128 programs of teacher training, 85 programs of open learning and five summer courses.

\section{The Queensland University of Technology (QUT) of Australia}

In comparison, the Queensland University of Technology (QUT) is one of Australia's largest universities with an enrolment of around 30,000 students. The university, for the majority of students, is an on-campus attendance university. The campuses are based in Brisbane, the capital city of the state, known as the "Smart State". QUT provides undergraduate and postgraduate courses up to doctorates from its three teaching campuses and also delivers courses in rural Australia and overseas.

\section{Objectives and Student Profiles}

The seven main objectives, explained in UNED's Charter Act, all contribute to the promotion of distance learning practices allowing greater opportunities for certain student profiles. García Aretio, (1996), reports: "distance learning students are normally of different ages, they have different qualifications and dispersed residences, they search for a way of independent learning, they work, they are mainly adults with little social interaction and partial dedication. They usually study at home or at work".

QUT's prime concerns and objectives are the quality of its teaching, the employability of its graduates and the application of its research for the benefit of the community at large. The University mainly serves Brisbane and South-east Queensland but has strong national and international links with more than 4000 international students attending courses at the University, and a 
growing number of local students completing part of their studies overseas through partnerships with institutions worldwide, (QUT Publications, 2002).

\section{Teaching styles}

In 1998, The UNED defined its educational model in the following terms,

“....it is based on the new learning theories under an experimental pedagogy, which considers that the direct professor-student relationship is not completely needed, since it is possible to learn certain scientific content alone. A methodology that guarantees the clarity and quality of main contents and provides the technological methods to assure fluid communication with the lecturer is needed. To reach this objective contrasts are needed with some pedagogical tools from an attendance university."

QUT in contrast, currently offers course delivery in the following modes:

Traditional classes e.g. 2 hour lecture 1 hour tutorial, 13 week semester, assignments, tutorials and laboratory work

Block courses eg overseas offerings consisting of extensive 4 day sessions, combining 13 weeks of a single unit into a 4 day delivery.

Combinations (sandwich offerings) of project/research/course work for some subjects.

Industry type training of a proprietary nature eg CISCO.

The main differences between the attendance and distance teaching models are summarised in Table 1.

Table 1. Attendance and distance teaching model differences (García Aretio, 1996)

\begin{tabular}{|c|c|}
\hline Attendance teaching & Distance teaching \\
\hline Lack of function diversification & Multiple units and functions \\
\hline Simple process of course production & Complex process of course production \\
\hline Administrative problems in the timetables & Co-ordination problems \\
\hline Many lecturers & Fewer lecturers \\
\hline Few administrative staff & Many administrative staff \\
\hline $\begin{array}{c}\text { Lack of ties between teacher-administrative } \\
\text { staff }\end{array}$ & Many ties between teacher-administrative \\
& staff \\
\hline More elitist and selective & Greater democratisation in access \\
\hline Many courses with few students & Many students in each course
\end{tabular}

\section{Organisational models}

The UNED organisational model tries to accommodate both the needs of a central organisation at the administrative and academic level, with the needs of a decentralised student population, by situating a central academic section in a university campus in Madrid, consisting of teams of lecturers in various departments. Associated centres are situated extensively over Spain and abroad. These centres offer academic support to students by providing tutorials close to the students' residence. These centres also offer video-conferences, conferences, seminars and scientific meetings. 
QUT on the other hand, for the majority of the students, has both functions on all of its three physical campuses.

\section{Communication Strategies Using Web-based Technologies}

The recent explosion of information and communication technologies has promoted the establishment of a different relation between lecturers and students. In the last few years new information and communication technologies have been taken up by both universities. These technologies are the result of applying computers and telecommunications to the educational landscape giving birth to what Cabanes, (1983) has called "training engineering"; that is a combination of materials, distribution channels and feedback systems amongst students and lecturers.

Since the main objective of UNED is a teaching style based on active learning the Internet is used in the following ways:

to enable an active way of learning

to offer additional means to learn

to develop a model of interaction and resources "on line” adapted to student needs

to promote ways of communication that enable the establishment of work groups amongst students and lecturers with the same interests by increasing the flow of information amongst them

to stimulate the use of available resources

to combine the offer of alternative techniques in the teaching organisation by promoting student independence

In order to achieve these objectives, an educational web should provide:

a search service

actualised documents

spaces for interaction and shared work

communication about various events

a glossary of terms

clear and structured documentation about main possibilities. In the portal all the available requirements must be specified so it should refer to a number of design rules that guarantees ease of use, efficient access and a main structure for navigation

the mechanisms for data warehousing which must establish a group of security measures and confidentiality according to main regulations

establish proper links from the main pages to others

develop a logical structure of pages in folders with related contents.

In order that students can actively participate, the tools that they require include:

a forum for people starting their subjects

a forum with complementary activities

a first solution service where the lecturer solves problems and other students can give personal opinions 
a forum of study

self-evaluation exercises

forums and distribution lists that help isolated students by providing them with contact with other students and lecturers.

In the UNED educational system the main applications of technology have therefore been in advanced phone applications, video-text, video-conference and the use of the Internet.

Advanced phone applications. Some years ago a 24-hour service of automatic response (SIRA) was introduced. Students can freely access information about the state of their matriculation, application forms and marks obtained in exams. Up to now many students have been able to access their marks via wap technology through their mobile phones. All the information about their subjects is found in the portal CampusWAP.com (http://campuswap.com). UNED has also recently developed phone access through the Internet (http://unedsat.uned.es). This service allows any UNED student to call the lecturers for the cost of a local phone call through the student's computer via the UNED portal to the lecturer's phone.

Video-text. In 1992, by using the Spanish net IBERTEX, video-text was introduced. It is publicly accessible and provides general information about the university, marks, pre-inscriptions, grants, courses and job offers. The information about different faculties is a restricted service accessed by passwords.

Video-conferencing. UNED was the first university in 1993 to adopt video-conferencing in Spain. Today the Educational Network of Video-conferences in the UNED is composed of 38 teams. A video-conference can be simultaneously held with more than one Associated Centre. This enables a richer relationship to be developed between a lecturer and student. From its inception video-conferencing has been widely adopted in the university. It has been used for work meetings between lecturers on the Central campus and Associate Centre tutors, as well as conferences specialising in different themes of actuality, presentations, project discussions and even some distance exams have been developed.

The Internet. The Internet is the most used multimedia support in the web documents. The UNED is connected via RedUUS network in the url http://www.uned.es. It presents a portal where all general information about the university is shown, allowing direct access to programs, lecturers and subjects. The main characteristics of the Internet (such as hypermedia, distributed, heterogeneous and collaborative systems) make it an ideal tool for:

Lectures

Tutorials

Email allows student questions to be quickly and easily answered. Distribution lists allow information of most frequently asked questions to be sent to all the subscribed students with the use of hypermail (Figure 1).

Virtual classes

By using distribution lists or chats, moderated forums can be established. The previous distribution of materials adds an interactive element that makes

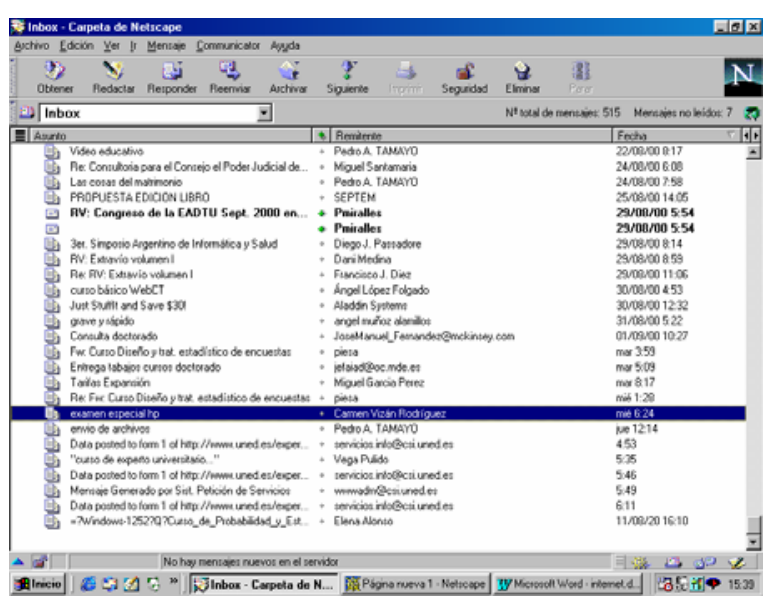

Figure 1. Distribution lists 
the virtual class close to a real one.

The news section.

Where students can interchange documents with the rest of the class. (Figure 2).

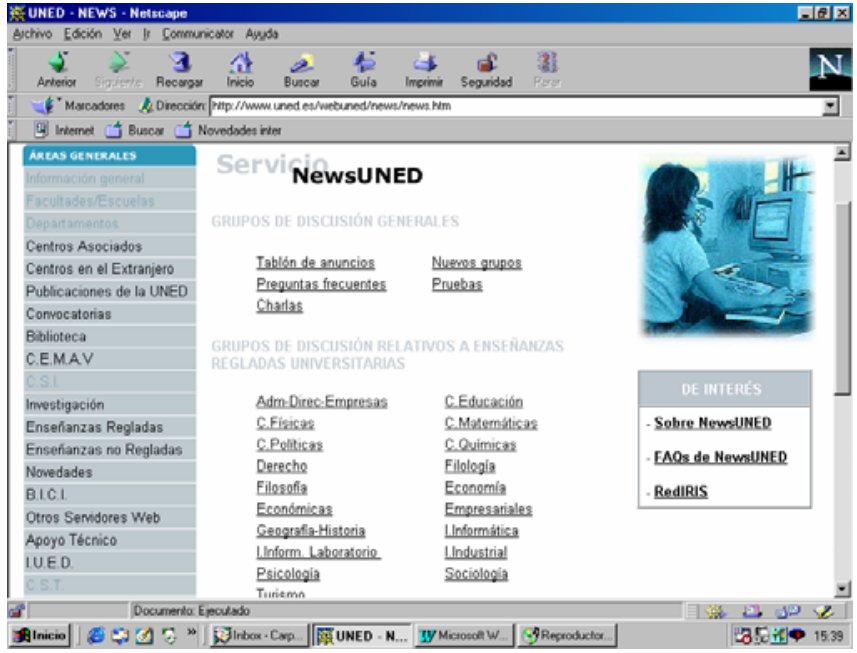

Figure 2. Main page of NewsUned

Forums. Due to the importance of research in diverse areas, a series of forums have been developed to promote the introduction of lecturers, tutors and interested students in projects, with pages of scientific information, collaboration and research projects. Personal lecturer pages have been developed for the lecturer and

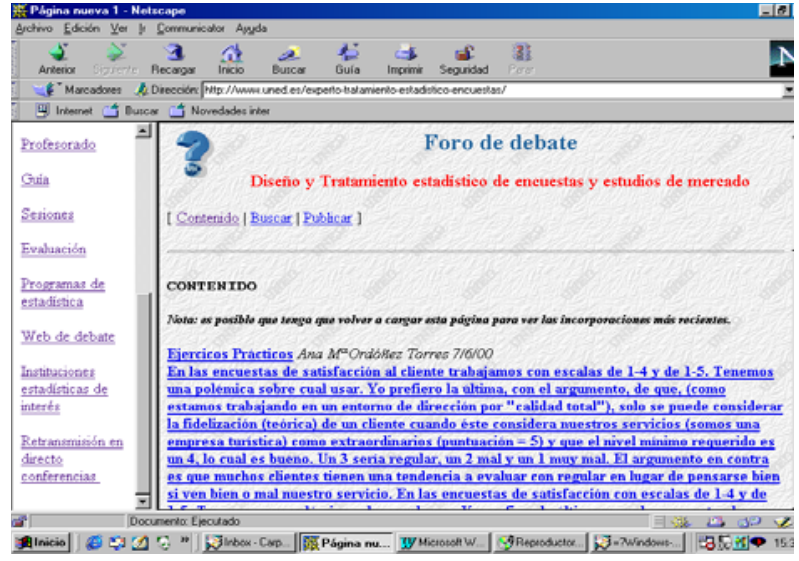

Figure 3. Research forums

TeleUNED. In 2000 UNED opened its own channel on the Internet called TeleUNED (http://www.teleuned.com). It is a multimedia platform that allows the direct transmission via the web of important academic events as well as "video on demand", such as video-cassettes and the production of educational television space, together with radio programs on the Internet, RadioUned (http://www.radiouned.com). TeleUNED is now an integral part of the university. The demand for these services has increased so TeleUNED and the Video-conference via the integrated service digital network (ISDN) are found together. 
Electronic Books. Another important service is the provision of electronic books. This has become the first virtual university bookshop in the Spanish language, Liberuned.com (http://www.liberuned.com). The advantages of ease of distribution and the associated price reduction are substantial, (Figure 4).

\section{The QUT internet based net- work}

The ubiquity of QUT's internet based network has somewhat dulled the boundaries between what might be alter-

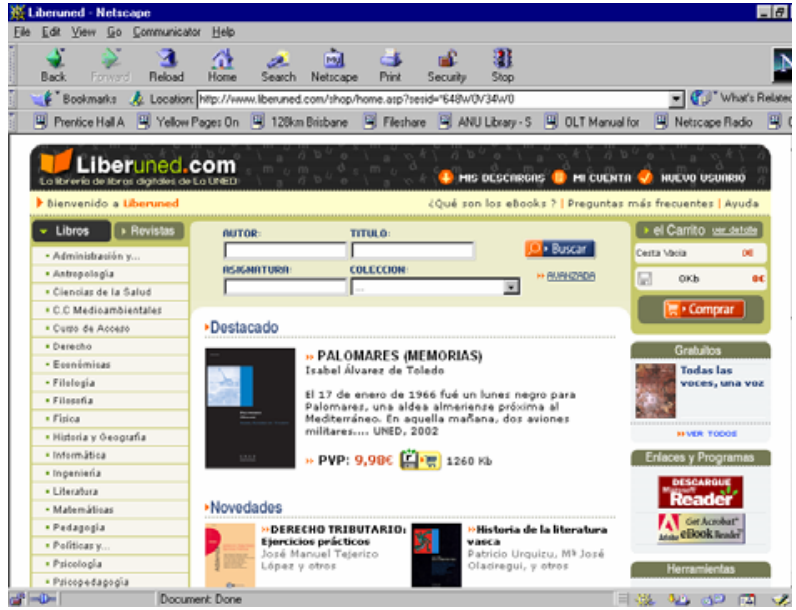

Figure 4 E-book librarv natively referred to as the QUT internet, intranet or extranet. Using whatis.com, (2002) definitions,

"The Internet is a public, cooperative, and self sustaining facility accessible to hundreds of millions of people worldwide which uses a portion of the total resources of the currently existing public telecommunications networks. It uses a set of protocols called TCP/IP and allows uses (with permission) to get information from other computers.

An Intranet is a private network that is contained within an enterprise, using the same protocols as the Internet which although having a main purpose of sharing organizational information can via gateway computers connect to the Internet.

An Extranet is a private network that uses the same protocols as the Internet but designed to securely share part of an organisation's information or operations with external parties such as clients. An extranet can be viewed as an intranet that is extended to users outside the organization.”

The aims for QUT's use of technology are

In teaching delivery:

oFor updating details of unit content, (OLT)

oReading allocations (either in full, via a Internet link or course materials database, CMD (updated by library staff on request)) (OLT)

oAccess to post-enrolment unit details, lecture notes, tutorial and assignment questions, (OLT)

oEstablishment of user groups for group emails (developed from enrolment lists) (email)

oStudent submission areas (for online submission of tutorials/assignments etc) (OLT)

oAccess to library facilities, on line databases, (Library)

Relating to the delivery of teaching and learning administration

oClass allocations (room and timetable maintenance) linked to teaching allocations (lecturers/tutors) (FITSIS)

oOn line searching of pre-enrolment course contents, times, classes, on-line enrolments, changes to enrolments, allocation to tutorial groups. (Virtual) 
oAccess to assessment marking, final grades (FITSIS)

oRequests to add CMD to OLT (OLT)

oAdding student individual assessment details (marks), final gradings (FITSIS)

oAccess to student personal details, academic history, GPA's, units enrolled, (Virtual)

Relating to the delivery of administrative support functions

oAccess to QUT Diary for planning of meetings (Diary)

oAccess to on line directories, staff, faculties, students, (Virtual)

oAccess to own personal details (salary details, holidays, entitlements) (Virtual restricted)

oFor marketing university/course/unit offerings-range of links from Internet enabled site detailing product offerings. (Virtual)

The internet based network is designed to service the general public with casual access for information and for pre-enrolment students. It also provides students with post-enrolment data such as allocation to units. Both the academic staff, lecturers and tutors as well as administrative and general support staff, librarians and technicians all use the network to accomplish their functions. The QUT internet based network is commonly referred to as the intranet but it should be made clear that its purpose and application encompasses the definitions of internet, intranet and extranet.

\section{Components}

\section{QUT main web page}

(Figure 5)

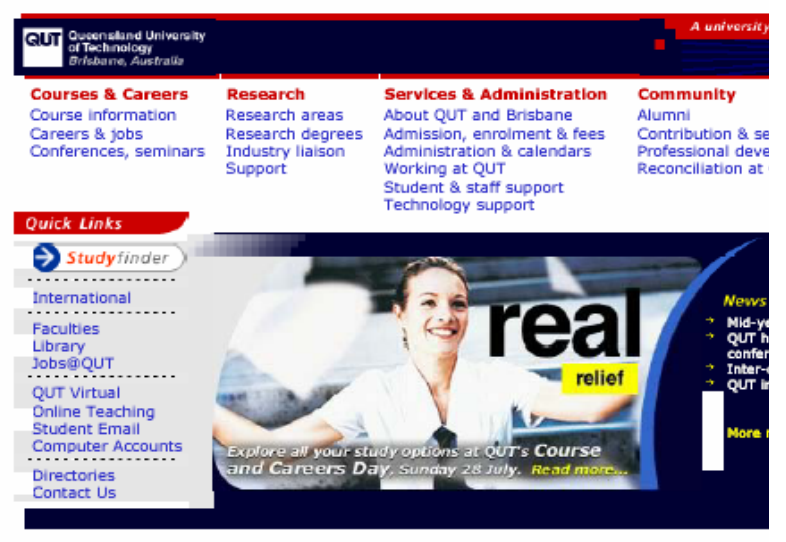

Figure 5 QUT Main Web page 


\section{On line teaching (OLT)}

(Figure 6)

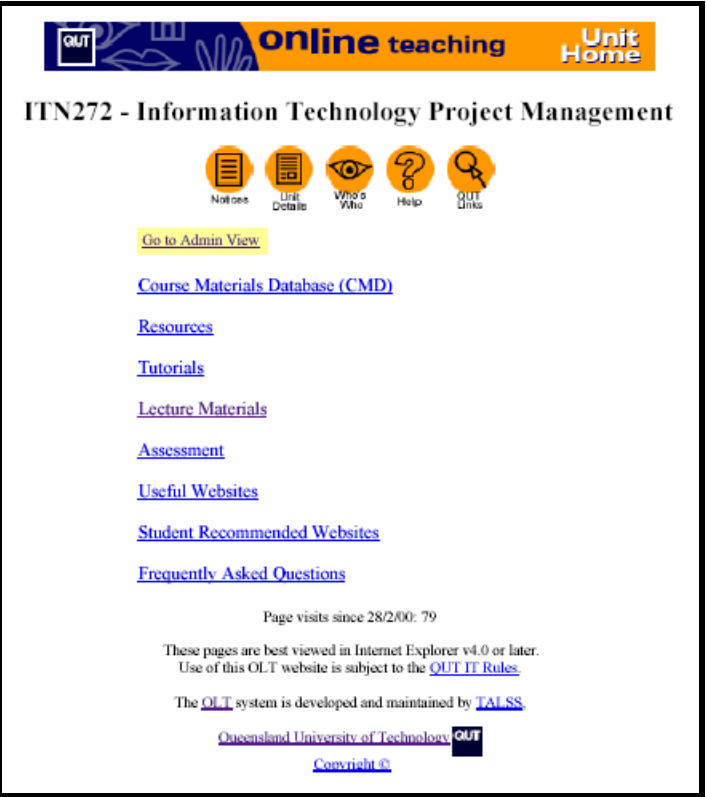

Figure 6 On Line Teaching Unit Page

\section{QUT Virtual}

(Figure 7)

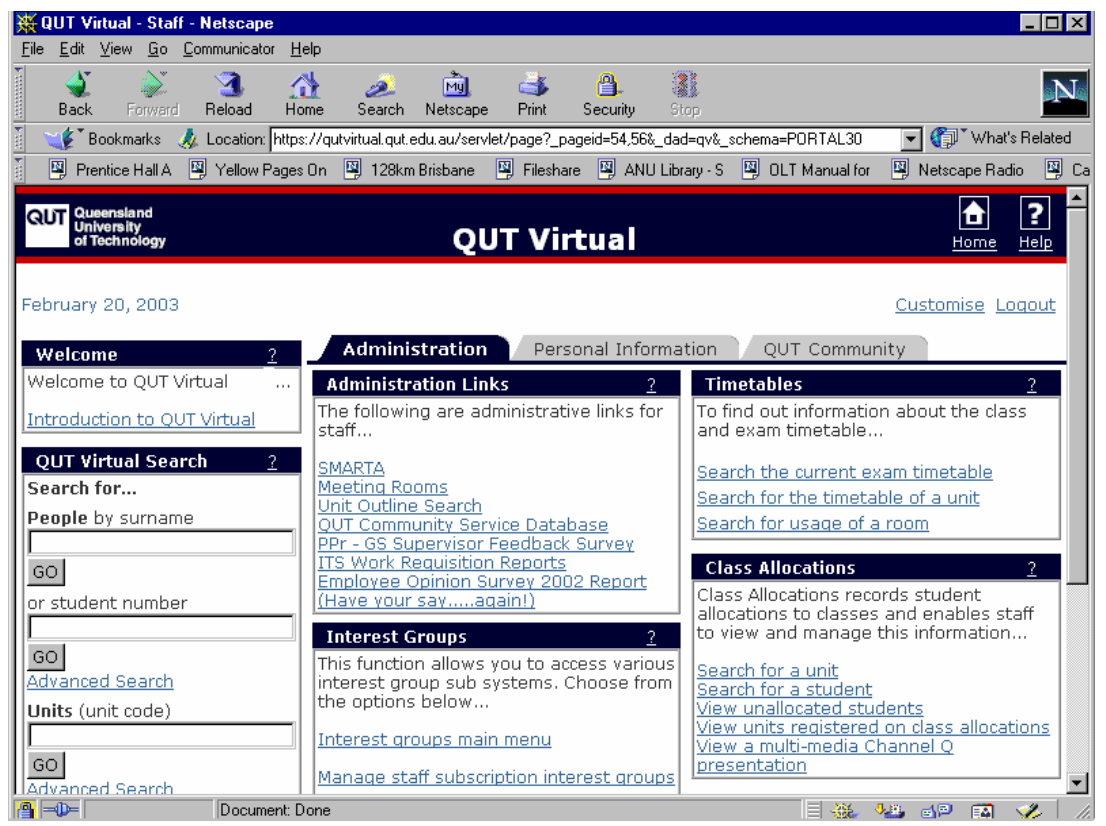

Figure 7 QUT Virtual Main Page 


\section{QUT library}

(Figure 8)

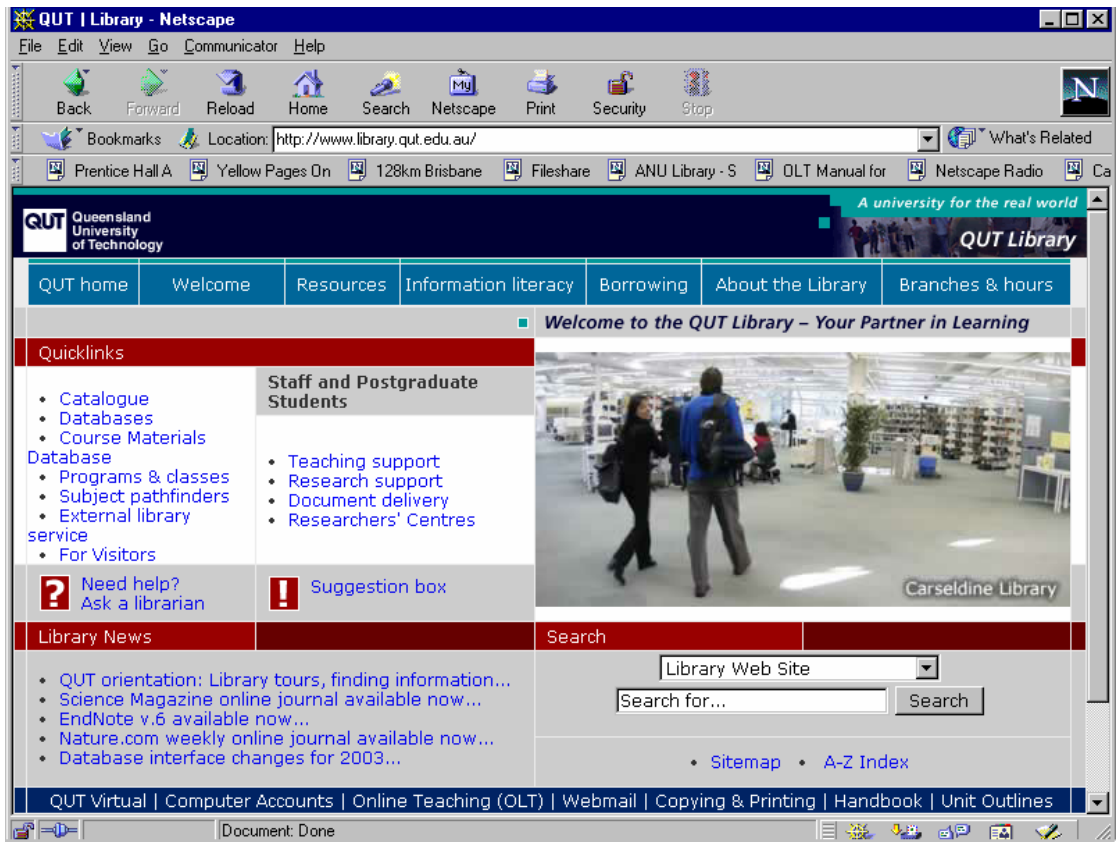

Figure 8 Library Main page

\section{FITSIS}

(Figure 9)

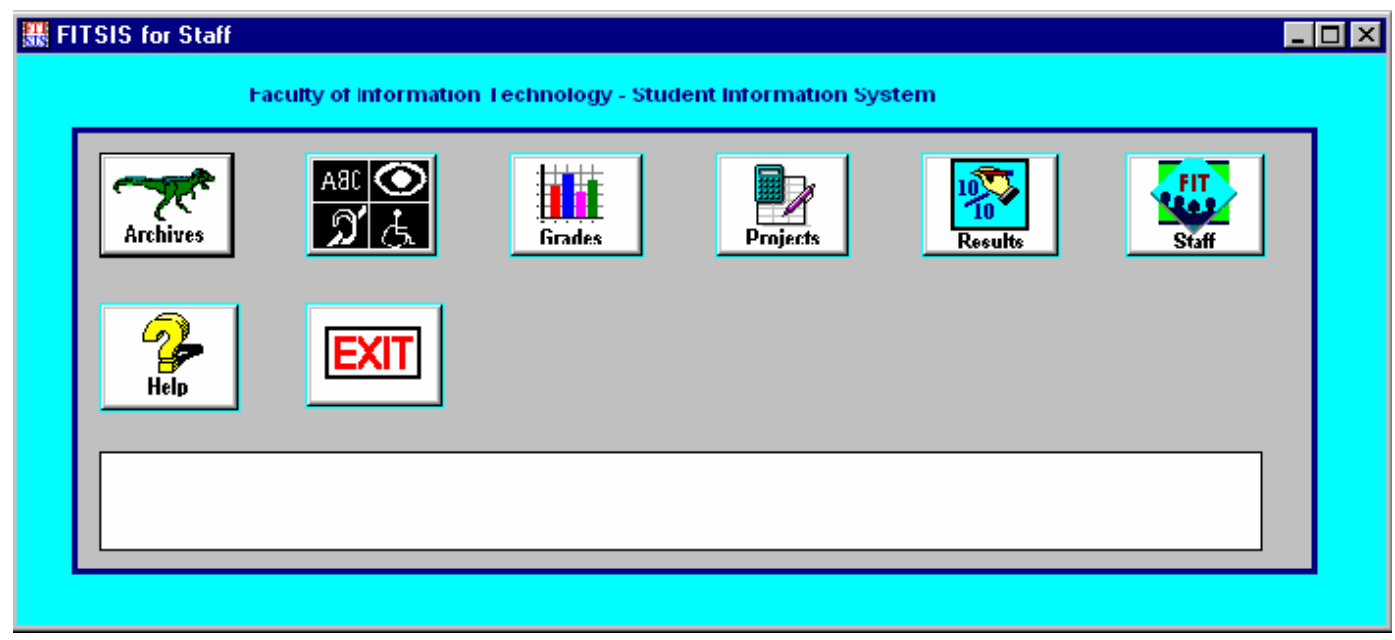

Figure 9 FITSIS Results Database

\section{QUT Diary}

Netscape Calendar 4.7.1 
Jewels, de Pablos Heredero, \& Campbell

\section{Email}

Qualcomm Eudora 4.3 Version 4.3.2

\section{How Organisations Develop Information Technology to Meet their Needs.}

So did the different teaching styles of these two universities drive their application of technology or did the technology impact on the teaching styles?

In a relatively short history there is an indication that organisations have adopted information technology in three distinct stages,

Using IT to improve productivity and quality (automate stage)

Creating or maintaining advantage through information technology (informate stage)

Redesigning business processes to better support company strategy (transformate stage)(Frenzel, 1999)

The importance placed on information/knowledge sharing at each stage could assist in identifying how the UNED and QUT's knowledge sharing practices have evolved and the effect this has had on their delivery of teaching styles using web-based technologies.

The Automate Stage. As an extension of Taylor's scientific management principles (Taylor, 1967), the application of IT was primarily used to reduce the cost of production. This "automate" stage, as it has become known, tended to replace workers who had been performing the same processes manually, with an IT automated process. The Taylorist view was that it was management who understood the processes that workers had been undertaking and who understood the links between all the various processes in the production chain. The workers themselves needed to be instructed on how to perform these tasks more efficiently and were not able, by themselves to develop more efficient ways of performing their tasks, (Grant, 1997).

The Informate Stage. In what was first termed the "informate" stage by Shoshana Zuboff, (1988) it was soon realised that automated processes yield information as by-products, (Scott Morton, 1991). This stage was destined to see the emergence of the "knowledge worker" described as

"People who create information and knowledge as part of their work and integrate it into the business and are responsible for finding and developing new knowledge for the organisation and integrating it with existing knowledge” (Turban et al., 2002).

The three distinguishing characteristics of the "informate" stage are:

The use of new tools providing information that must be used to get the job done

The new IT tools often generate new sorts of information as a by-product

New skills and information can be developed to open up new opportunities, (Scott Morton, 1991). A move away from the physical "feel" of manual skills towards the symbolism or meaning of the data generated from computer generated processes is how Zuboff, (1988) distinguishes these two stages. This perceptual view of information emphasizes the importance of analytical and interpretive skills in technology use promoting a view of technology that is people focused (Brooke, Ramage, Bennett, \& Gold, 1998). They conclude that an organization's preference for a resource versus a perceptual view of information (or a mixture of the two) will result in different technological choices. The significant difference from the "auto- 
mate” stage was an implicit acceptance by management that workers were able to provide worthwhile knowledge regarding their activities.

The Transformate Stage. There is a need however, to adopt a totally different approach for the design and application of applications that transform work processes, organisations and industries from that used to automate existing business systems and structures, (Applegate, McFarlan, \& Mckenney, 1999). Three different types of transformation are discussed by Blumenthal and Haspeslagh, (1994),

Improving Operations

Strategic Transformation

Corporate Self-Renewal

According to Scott Morton, (1991) this stage is characterised by leadership, vision and a sustained process of organisation empowerment "so basic to be exceptionally hard to accomplish" (p17). Essentially the argument put forward by Scott Morton was that long term benefits from IT could only come from applying it in a way that literally transforms the business, although it is always very tempting and simpler to merely achieve efficiency through automation.

\section{How UNED and QUT Developed their Technology}

\section{UNED}

In developing UNED's technology different technological solutions such as Hot Potatoes, Perception Scientific Notebook, WebCT, LearningSpace, TopClass, ToolBook, CourseInf were considered. Two criteria relating to system management were cost-benefit analysis and support. In addition, user considerations of lecturing capability, ease of use, and flexibility were considered. The WebCT (Web Course Tools) met all these criteria. It was developed by Universal Learning Technology, and comprises a number of very concrete functions and well defined objectives through a structured tree shape interface, a non-complex one that can be used by non-experts, (Figures 10 and Figure 11).

WebCT uses standard navigation technology for student access and the design tasks the lecturer needs to develop. It incorporates, a) email, a system of conferences, b) on line speech, c) management of courses, d) evaluation/exams, e) ease of configuration by using the interface (colours, page design); f) a group of educational tools to enable learning (as for example, student presentation), the communication and collaboration; g) a series of administrative tools to help the lecturer with course distribution.

In general terms, the WebCT includes the following data: a) multimedia possibilities, b) tools for student self-evaluation and "on line" evaluation; c) maintenance and marks distribution; d) it allows moderate discussions; e) electronic mail system; f) supervision the course; g) active links via Internet; h) possibilities of real time chats; I) areas of student presentation and creation of pages of presentation; $j$ ) design tools and course management tools; k) security and access control by user identification and passwords; K) the creation of security copies.

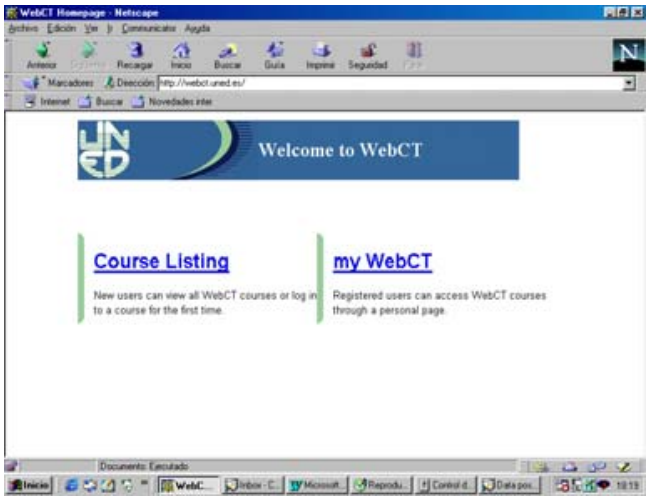

Figure 10. Main page of WebCT 
The structure of this tool is made up of a group of programs in the server (http://webct.uned.es) receiving requests for materials and services from interactions between lecturers and students using the system, while at the same time, allowing personal storage of material that they use in answering questions.

It combines existing resources in the university (e.g. exams, works, queries, etc.) with ones typical in the tool (chats, forums, hypermedia materials, etc.) while at the same time, leaving all the implementation, organisation and evaluation in lecturer's hands.

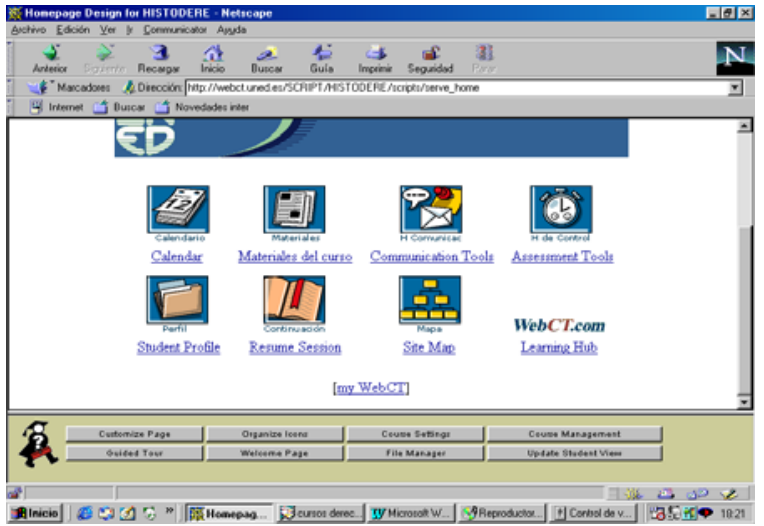

Figure 11. Main menu in WebCT

\section{QUT}

QUT on the other hand, has developed an elaborate Internet based network that is being extensively utilised by a variety of stakeholders. There are benefits and limitations of this Internet based network in terms of its capability to share knowledge and its subsequent ability to contribute towards one of the university's primary objectives, that of teaching.

Although there are a few examples of applying web based technology for teaching in new ways, eg the Faculty of Education has developed and trialled a virtual workplace where videoconferencing and web technologies are used to allow pre-service education students to observe and interact with classroom teachers in schools, a significant amount of information contained on the QUT internet based network is merely digitised copies of printed documentation.

Undoubtedly the application of QUT's web based technology has provided an environment where all stakeholders have greatly benefited from a more efficient information delivery medium. Yet, the information itself is essentially the same information that would have been distributed if an internet based delivery medium did not exist.

For any university to not apply what has become a ubiquitous communication medium would undoubtedly run the risk of it losing stakeholder credibility. The use of an internet based network which might at one stage have contributed to an organisations' strategic advantage has, over time, evolved into what is probably now only commodity status.

\section{Application to the UNED and QUT Internet based Network}

The application of the Internet based network in both universities is still clearly, predominantly in the "automate" stage of IT adoption although some examples of "informate" type activities are also noticeable. Although attempts have been made to use the both Internet based networks as a means to "transformate", success in doing so has been negligible. Maybe some difficulties come from the needed duplication of parallel processes as an effort coming from both universities with the main aim of offering more alternatives to students that traditionally have been familiarised with ancient procedures and the lack of use of web based technologies.

Perhaps one of the difficulties in moving to the next stage is because of the way the networks have been developed. Neither the UNED nor the QUT Internet based networks were originally designed as strategic tools that would meet all the needs of university stakeholders without redundancy. The group of applications which make up the both universities Internet based networks 
have been in the main the individual initiatives of a number of departments. Essentially, they are maintained exclusively by their departmental creators and some redundancy of information is evident. This is only considered a problem when stakeholders discover conflicting information.

In both cases, the design strategy of the Internet based network was therefore more of a bottom up rather than a top-down approach. Similar to any bottom-up design strategy in IT/IS development the inherent weakness is in the requirement that eventually some sort of an integration must occur between the various components, (Sommerville, 1995).

Davenport, (2000), suggests that Rapid "Sense and Respond” Business Models, also referred to as "lean production", "mass customisation” or "customer-centric" models has been widely predicted. However, neither universities' application of these principles has been apparent to date.

An early attempt to apply the QUT Internet based network to distance education in an information technology course was unsuccessful. It was believed by administrators that the delivery of an external course using materials initially developed for internal delivery could be achieved by using the QUT Internet based network simply as the delivery medium. As no significant additional resources were allocated for this external course, it became a considerable burden to the academic staff assigned to it. It was quickly realised that even though some students were undertaking these external courses from remote areas, the majority of students were still from the Brisbane metropolitan area. Although it was recognised that the reason these students were prepared to pay a premium for undertaking external rather than an internal delivery was that they were, because of work commitments, unable to guarantee their attendance at set teaching times, the offering was still considered to be in competition with the university's attendance mode. The opportunity for QUT to develop another type of teaching delivery mode, possibly by using a combination of its existing modes, in which use of the QUT Internet based network will be a fundamental component, is still being considered, but in its original form the distance course was withdrawn after only a few years.

Academic staff's use of the UNED and QUT Internet based network, in addition to contributing to operational efficiencies does provide the opportunity to contribute significantly to the quality of teaching offered. The term "real-time planning" at an operational level, described by Schwarzkopf, (1992), can be applied in terms of the speed in which new research can be integrated into both universities' teaching curriculum. The use of the Internet based network in this manner follows the theme of Gates, (1999), when he suggests that "the tools and connectivity of the digital age now give us a way to easily obtain, share and act on information in new and remarkable ways”. (pxvii)

However, a significant amount of information is contained on both universities Internet based networks that is merely digitised copies of printed documentation. Although it is still possible to obtain hard copies of this type of documentation, the digitised versions, are more efficient for retrieval as well as being more up to date.

\section{The Future}

Social, economic, technical and market forces may be driving changes in higher education, more rapidly than the capacity of institutions to adapt; possibly caused by the traditions of shared governance in which power is equally shared amongst potential decision makers, (Duderstadt, 2000). "While information technology has the capacity to enhance and enrich teaching and scholarship it also poses certain threats to our colleges and universities" (p148).

Achieving any quality product or service requires that knowledge workers share data, information and experiences, and in order to optimise knowledge sharing, as well as having a supportive culture an organisation must possess a suitable infrastructure, (Gross, 2001). Information technology 
Jewels, de Pablos Heredero, \& Campbell

is considered by many institutions as a goal within itself, with its own outmoded measures of success. Katz, (2000) proposes that information technology on its own serves no useful purpose if it is not serving the needs of fundamental educational endeavours.

\section{Conclusions}

Today, technologies are increasingly bi-directional and allow more interaction between lecturers and students as well as amongst students. Communications via the Internet and electronic mail are two actual examples of this interactive focus in the teaching of distance students. The application of these multimedia technologies to distance learning modes shows new alternatives for communication. They offer more flexible and accessible distance learning with quality content. The main critical success factor is situated in a proper pedagogical management of the developed processes with the decisive support of the most adequate technology.

Both lecturer/professors and students would find it difficult to now visualise teaching and learning without the use of the different universities' Internet based networks. It undoubtedly already contributes significantly to both organisations' objectives, despite the predominance of the different teaching styles each university utilises.

The existing infrastructure does exist to blend both universities Internet based networks into new and exciting business models that stakeholders may one day demand. An understanding by all stakeholders of the potential that the Internet based networks offer for knowledge sharing appears to be a necessary prerequisite to further development of this potential.

Therefore there is a case that although these universities have utilised different aspects of technology to support distance education and on campus attendance, they are both at the same automate stage. This lends some weight to the proposed hypothesis that it is indeed educational philosophy and teaching styles which are driving the application of the technology and not the other way around.

\section{References}

Alavi, M. (1994). Computer-mediated collaborative learning: An empirical evaluation, MIS Quarterly, 18 (2), 150-174.

Alavi, M., Wheeler, J. \& Valacich, J. (1995). Using IT to reengineer business education: An exploratory investigation of collaborative tele-learning, MIS Quarterly, 19 (3), 294-312.

Applegate, L. M., McFarlan, F. W. \& Mckenney, J. L. (1999). Corporate information systems management: Text and cases (5th ed.). Boston, MA: Irwin McGraw-Hill.

Block, H. \& Dobell, B. (1999). The e-Bang theory, Education industry overview. Bank of America Securities, Montgomery Division, San Francisco CA.

Blumenthal, B. \& Haspeslagh, P. (1994). Toward a definition of corporate transformation, Sloan Management Review, 35 (3), 101-106.

Brooke, C., Ramage, M., Bennett, K. \& Gold, N. (1998). Change effects and legacy information systems: A framework to aid our understanding. Proceedings of Information Systems: Current Issues and Future Changes, Helsinki, Finland, December $12^{\text {th }}$.

Cabanes, R. (1983). Experiencia y reflexiones sobre tecnología educativa en la empresa. UNED, Madrid.

Davenport, T. H. (2000). Mission critical: Realizing the promise of enterprise systems. Boston: Harvard Business School Press. 
Duderstadt, J. J. (2000). Between a rock and a hard place: Leading the university during an era of rapid change. In M. Devlin, R. Larson \& J. Meyerson, J. (Eds.), The Internet and the University 2000 Forum, Forum for the Future of Higher Education and EDUCAUSE, Boulder CO.

Frenzel, C. W. (1999). Management of information technology (3rd ed.). Canada: Course Technology.

García Aretio, L. (1996). La educación a distancia y la UNED, Estudios de Educación a Distancia, 21, 3042.

Gates, B. (1999). Business @ the speed of thought. St Ives, UK: Penguin Books.

Grant, R. M. (1997). The knowledge-based view of the firm: Implications for management practice. Long Range Planning, 30 (3), 450-454.

Gross, A. E. (2001). Knowledge sharing--The crux of quality. Proceedings of Annual Quality Congress, Quality, A. S. f., Milwaukee,

Katz, S. N. (2000). Don't confuse a tool with a goal. In M. Devlin, R. Larson \& J. Meyerson, J. (Eds.), The Internet and the University 2000 Forum, Forum for the Future of Higher Education and EDUCAUSE, Boulder CO.

Knoll, K. \& Jarvenpaa, S. (1995). Learning to work in distributed global teams. Proceedings of 28th $\mathrm{Ha}$ waii International Conference System Science, Maui, Hawaii.

Leidner, D. \& Fuller, M. (1997). Improving student learning of conceptual information: GSS supported collaborative learning vs individual constructive learning. Decision Support Systems, 20 (2), 149-163.

Leidner, D. \& Jarvenpaa, M. (1993). The information age confronts education: Case studies on electronic classrooms. Information Systems Research, 4 (1), 24-54.

QUT Publications (2002). Queensland University of Technology annual report 2001 Volume 1, QUT, Brisbane, 32 pages

Schwarzkopf, H. N. (1992). It doesn't take a hero. New York: Bantam Books.

Scott Morton, M. S. (1991). The corporation of the 1990's. USA: Oxford University Press.

Sommerville, I. (1995). Software engineering (5th ed.). USA: Addison-Wesley.

Taylor, F. W. (1967). The principles of scientific management. New York: Norton.

Turban, E., McLean, E. \& Wetherbe, J. (2002). Information technology for management (3rd ed.). USA: John Wiley.

Venkatraman, N. (1994). IT-enabled business transformation: From automation to business scope redefinition. Sloan Management Review, (Winter), 73-87.

whatis.com (2002). SearchSecurity.com definitions. TechTarget. Retrieved 2 August 2002 from http://whatis.techtarget.com/sDefinition

Zuboff, S. (1988). In the age of the smart machine: The future of work and power. Oxford, UK: Heinemann.

\section{Biography}

Tony Jewels is a lecturer within the School of Information Systems at the Queensland University of Technology. An IT professional for over 30 years, he has worked in a variety of roles on leading edge IT projects throughout the world and currently coordinates the undergraduate and postgraduate IT Project Management units at QUT. He is currently researching motivations for knowledge sharing in IT project teams.

Dr Carmen de Pablos Heredero is an Associate Professor at the Rey Juan Carlos University, Madrid, Spain. She specialises in the impact of IT on organisational performance and has pub- 
lished books and articles on that topic for the last 10 years. She has also worked as a consultant in organisational problems for insurance companies for Primma worldwide.

Dr Marilyn Campbell is a lecturer within the Faculty of Education at the Queensland University of Technology preparing school counselors in the Masters of Education program. Previous to this, she supervised school counselors and has worked in early childhood, primary and secondary schools as a teacher, teacher-librarian and school counselor. Her main clinical and research interests are the prevention and intervention of anxiety disorders in young people. 